\title{
THE HEPATOPROTECTIVE EFFECT OF NITRIC OXIDE ON MURINE SCHISTOSOMIASIS MANSONI
}

\author{
SBy \\ Samar M. Alhusseiny *, Samar N. El-Beshbishi *, \\ Maha M. Abu Hashim **, Hosam El-dein E. El-nemr *, \\ Abeer A. El-Henawy *, Aya E. Handoussa \\ Trom \\ * Department of Medical Parasitology, Faculty of Medicine, \\ Mansoura University, Mansoura 35516, Egypt \\ ** Department of Pathology, Faculty of Medicine, \\ Mansoura University, Mansoura 35516, Egypt
}

\begin{abstract}
Background: Schistosomiasis is a major public health problem in developing countries. Currently, praziquantel (PZQ) is the drug of choice for human schistosomiasis. Isosorbide-5-mononitrate (IS-5-MN) is a nitro compound that is used as an antianginal remedy. It must be enzymatically metabolized to release nitric oxide (NO) to exert its pharmacologic activities. This study evaluates the vasodilator effect of the NO donor IS-5-MN on hepatic bilharzial lesions caused by Schistosoma mansoni, and determines whether the combined use of IS-5-MN and $P Z Q$ is synergistic or antagonistic.
\end{abstract}

Methods: Swiss albino female mice (CD I strain) were divided into five groups: (i) non-infected; (ii) infected non-treated; (iii) infected and treated with PZQ, 6 weeks post infection (WPI) in a dose of $500 \mathrm{mg} /$ $\mathrm{kg} /$ day for two successive days; (iv) infected and treated with IS-5-MN from the fourth to the tength WPI 5 days $/$ week in a dose of $10.08 \mathrm{mg} / \mathrm{kg}$; (v) infected and treated with IS-5-MN as group (iv) in addition to PZQ as group (iii). Parasitological, biochemical and histopathological parameters that assess disease severity and morbidity were investigated.

Results: PZQ significantly inMANSOURA MEDICAL JOURNAL 
creased the percentage of dead eggs, decreased granuloma number but did not reduce granuloma diameter. IS-5-MN administered alone did not induce a shift in the oogram pattern, but it reduced inflammation, necrosis and granuloma diameter. The simultaneous administration of both drugs significantly increased NO level in liver homogenates and induced modulation of granuloma size. The best results were obtained in the mice group treated with IS-5-MN in addition to $P Z Q$.

Conclusions: Our results point to IS-5-MN as a promising medication that could be used as a combined therapy with $\mathrm{PZQ}$ to ameliorate schistosomal liver pathology. Further studies are recommended to explore effects of IS-5-MN and PZQ coadministration in schistosomiasis advanced liver fibrosis.

Keywords: Schistosoma mansoni, liver fibrosis, isosorbide-5mononitrate, praziquantel, nitric oxide, granuloma.

\section{INTRODUCTION}

Schistosomiasis is a tropical parasitic disease caused by genus Schistosoma [1]. In spite of the hard control efforts, schistosomiasis remains a major health problem that ranks with malaria and tuberculosis as a major source of morbidity affecting almost 240 million people worldwide [2].

The main lesions in chronic infection are caused by a complex delayed-type hypersensitivity response to sequestered viable, dying or dead ova that are trapped in the tissues. The eggs secrete proteolytic enzymes that induce eosinophilic inflammatory and granulomatous reactions, which are progressively replaced by fibrous tissue [3].

Schistosomal liver fibrosis results from an intense accumulation of collagen fibrils in the periportal spaces, leading to pathognomonic periportal or Symmer's pipestem fibrosis with its consequences e.g. portal hypertension, splenomegaly, collateral venous circulation, portocaval shunting, and gastrointestinal varices [4]. Liver fibrosis is initiated by hepatic injury; hepatocyte damage releases cytokines such as transforming growth factor- $\alpha$ (TGF- $\alpha$ ), and tumor necrosis factor- $\alpha$ (TNF $\alpha$ ) [5]. In turn, the principle masters of liver fibrosis 
Samar M. Alhusseiny et al...

i.e. hepatic stellate cells (HSCs) are stimulated [6] and transform into myofibroblasts [7].

Nitric oxide deficiency had been linked to liver fibrosis [8]. NO can induce apoptosis of activated HSC and inhibit their proliferation, motility, and contractility in addition to reducing excessive extracellular matrix (ECM) in fibrotic liver [9]. Besides, it impairs the release of inflammatory mediators [10], improves intrahepatic vascular response to portal blood flow [11] and leads to suppression of pro-inflammatory cytokines such as interferon- $\alpha$ (IFN- $\alpha$ ) and TNF- $\alpha$ [12]. Consequently, NO donors can exert an anti-fibrotic action as documented in previous studies [13]. IS-5-MN is the most commonly used long-acting NO donor and one of the most frequently used drugs in the treatment of coronary artery disease characterised by well tolerance and lack of serious side effects [14].

Thus, the aim of this study was to evaluate the effect of the NO donor IS-5-MN on hepatic lesions caused by $S$. mansoni and to determine the effect of PZQ and IS-5-MN coadministration.

\section{MATERIAL \& METHODS}

I. Animals, parasites and infection

All animal studies were approved by the Medical Experimental Research Center (MERC), Faculty of Medicine, Mansoura University, Mansoura, Egypt, based on the institutional and national regulations for animal experimentation.

A total of 67 Swiss albino female mice of CD I strain (aged 6-8 weeks, and weighting 20-25 gm) were purchased from the Schistosome Biological Supply center (SBSC), Theodor Bilharz Research Institute (TBRI), Imbaba (Giza), Egypt. Mice were infected with $S$. mansoni cercariae Egyptian strain, freshly shed from infected Biomphalaria alexandrina snails, purchased from the SBSC, TBRI, after exposure to light for 30 minutes. Each mouse was subcutaneously infected with $60 \pm 10$ cercariae [15].

Mice were kept in an airconditioned animal house (MERC) at 20-22 ${ }^{\circ} \mathrm{C}$, with $12 \mathrm{~h}$ light and $12 \mathrm{~h}$ dark cycle, and maintained on a standard commercial pellet diet, normal drinking water ad libitum.

MANSOURA MEDICAL JOURNAL 
II. Drugs and treatment regimens

Isosorbide-5-mononitrate (Effox, Minapharm, Egypt), and praziquantel (Biltricide, Alexandria Co. for Pharmaceuticals \& Chemical Industries, Egypt) were used in the study. The dose of IS-5-MN used for mice was equivalent to the highest dose, which induced improvement in rat model of carbon tetrachloride (CCl4)-induced liver injury [13]. According to Paget and Barnes [16] drug conversion tables, IS-5-MN dose used for mice was calculated to be $10.08 \mathrm{mg} / \mathrm{kg}$. It was administered from the fourth to the tength WPI, 5 days/week. PZQ was ground and used as a freshly prepared aqueous suspension in $2 \%$ Cremophor El (Sigma Chemical Co., St. Louis, MO, USA), and was given $6 \mathrm{WPI}$ in a dose of $500 \mathrm{mg} / \mathrm{kg} /$ day for two successive days [17]. Drugs were administered by oral gavage using a mouse feeding needle (Kent Scientific Corporation), in a volume of 200 $\mu \mathrm{l} / \mathrm{mouse}$.

\section{Animal groups}

Mice were randomly allocated into five groups, each of 10-15 mice at the beginning of the experiment:

- Group I: normal, non-infected $(n=10)$.
- Group II: infected non-treated ( $n=14)$.

- Group III: infected and treated with PZQ $(n=13)$.

- Group IV: infected and treated with IS-5-MN ( $n=15)$.

- Group V: infected and treated with IS-5-MN and PZQ ( $n=15)$. Mice in all groups were euthanized at the end of the study, 10 WPI.

\section{Parasitological study}

After euthanasia, the peritoneal cavity was opened to obtain fragments from the small intestine and the percentages of the different egg developmental stages (oogram pattern) were examined [18].

V. Biochemical study on liver homogenates

Nitric oxide level was assessed in liver homogenates using a commercially available kit (Catalogue number NO 25 32, Biodiagnostics, Dokki, Giza, Egypt).

\section{Histopathological studies}

Liver portions from euthanized mice were fixed in $10 \%$ neutral buffered formalin, and processed to paraffin blocks. Sections were cut $5 \mu \mathrm{m}$ 
thick, and then stained with haematoxylin and Eosin (H\&E) to evaluate histopathological changes. Lobular inflammation was graded [19] from 0-3 based on inflammatory foci per 200* magnification $(0=$ none; $1=$ $1-2 / 200^{*} ; 2=$ up to $4 / 200^{*} ; 3=>4 /$ $\left.200^{*}\right)$. Focal necrosis in liver cells around the central vein away from granuloma was scored [20] as follows: none $(0 \%)$; minimal $(1-10 \%)$; mild (11-30\%); moderate (31-60\%); and marked (> $60 \%$ of liver cells were affected). Inflammatory cellular infiltrate [21] was evaluated in five microscopic fields of highest inflammatory intensity at $40 x$ magnification and graded as follows: minimal ( $\geq$ $25 \%$ inflammatory cells); mild (26-50\%); moderate (51-75\%); and marked (> 75\%).

\section{Statistical analysis}

Data were analyzed using statistical package for social sciences (SPSS) software (SPSS Inc., Chicago, IL, USA), version 21. Continuous variables were presented as mean \pm standard deviation (SD) for parametric data, and median for nonparametric data. Analysis of variance (ANOVA) followed by Tukey's test were used to compare means of more than 2 groups (parametric data), while Kruskal Wallis (KW) test was used to compare the median of more than two groups (nonparametric data). Comparison between categorical variables was carried out using Chi-square test. The results were considered significant when the probability of error is equal to or less than $5 \%(p \leq 0.05)$, and highly significant when the probability of error is equal to or less than $0.1 \%(p \leq 0.001)$.

\section{RESULTS}

\section{Parasitological study}

Treatment of mice with PZQ 6 WPI significantly decreased $(P \leq$ 0.01) the percentage of mature eggs, caused complete absence of immature eggs and significantly increased ( $P$ 0.000) the percentage of dead eggs. IS-5-MN administered in a dose of $10.08 \mathrm{mg} / \mathrm{kg}$ for 5 weeks starting from the 4 th to the 10th WPI 5 days/week caused no reduction in the percentage of dead eggs, no reduction in the percentage of immature eggs and did not increase the percentage of dead eggs. Combined administration of IS-5-MN and PZQ induced complete absence of immature eggs and significantly increased $(P<0.05)$ the percentage of dead eggs (Table 1).

MANSOURA MEDICAL JOURNAL 
II. Biochemical study on liver homogenates

Nitric oxide assay

Infection of mice with S. mansoni significantly decreased $(P<0.05)$ NO level (Table 2), in comparison with non-infected group. Combined administration of IS-5-MN and $\mathrm{PZQ}$ significantly increased $(P=0.000)$ NO level by $289.47 \%$, when compared to infected non-treated mice.

\section{Histopathological studies}

Histopathological examination of the liver sections from infected nontreated mice showed preserved architecture, moderate inflammation of liver parenchyma, moderate focal necrosis, moderate inflammatory cell infiltrate, and a large number (Figure 1A) of irregularly outlined granuloma (Figure2A).

Administration of $\mathrm{PZQ} 6 \mathrm{WPI}$ caused no amelioration of the parenchymatous changes, when compared to infected non-treated group. However, it decreased the number of granuloma (Figure 1B) but did not reduce their size (Figure2B).

On the other hand, IS-5-MN led to significant amelioration of the parenchymatous changes. Liver sections exhibited mild inflammation of liver parenchyma, mild focal necrosis, significantly diminished inflammatory cell infiltrate, evident granuloma circumscription, and reduced granuloma diameter (Figure 2C), when compared to infected non-treated mice.

In addition, the combined administration of IS-5-MN and PZQ significantly diminished inflammatory cell infiltrate and reduced granuloma count and diameter (Figure2D). 
Samar M. Alhusseiny et al...

Table (1): Effect of praziquantel and isosorbide-5-mononitrate alone and in combination on oogram pattern in different mice groups.

\begin{tabular}{cccc}
\hline & \multicolumn{3}{c}{ Oogram } \\
\cline { 2 - 4 } Animal groups (number of \\
\cline { 2 - 4 } mice) & Mature \% & Immature \% & Dead \% \\
\hline Infected non-treated $(n=13)$ & 54.28 & 45.71 & 0 \\
PZQ $(n=13)$ & $14.28^{*}$ & $0{ }^{* * *}$ & $85.71^{* *}$ \\
IS-5-MN $(n=9)$ & 52.17 & 47.82 & 1.61 \\
IS-5-MN + PZQ $(n=13)$ & 41.67 & $0^{* * *}$ & $58.33^{* * *}$ \\
\hline
\end{tabular}

Values are expressed as medians.

* Significant difference from infected non-treated group at $p \leq 0.01$.

** Significant difference from infected non-treated group at $p 0.000$.

$* * *$ Significant difference from infected non-treated group at $p<0.05$.

Table (2): Effect of praziquantel and isosorbide-5-mononitrate alone and in combination on nitric oxide level in liver homogenates in different mice groups.

\begin{tabular}{lc}
\hline $\begin{array}{l}\text { Animal groups }(\text { number } \\
\text { mice) }\end{array}$ & NO level $(\boldsymbol{\mu m o l} / \mathbf{L})$ \\
\hline Non-infected $(n=10)$ & $3.488 \pm 1.491$ \\
Infected non-treated $(n=13)$ & $2.146 \pm 0.444$ \\
PZQ $(n=13)$ & $2.522 \pm 0.479(17.52)$ \\
IS-5-MN $(n=9)$ & $2.203 \pm 2.07(0.03)$ \\
IS-5-MN + PZQ $(n=13)$ & $8.358 \pm 2.284\left(289.47^{* * *}\right)^{\text {a }}$ \\
\hline
\end{tabular}

Values are expressed as means \pm SD.

Values enclosed in parentheses refer to the percentage of increase compared with infected non-treated group.

* Significant difference from infected non-treated and IS-5-MN-treated groups at $p$ 0.05 .

** Significant difference from infected non-treated group at $p 0.000$.

a Significant difference from non-infected, PZQ and IS-5-MN-treated groups at $p$ 0.000 . 

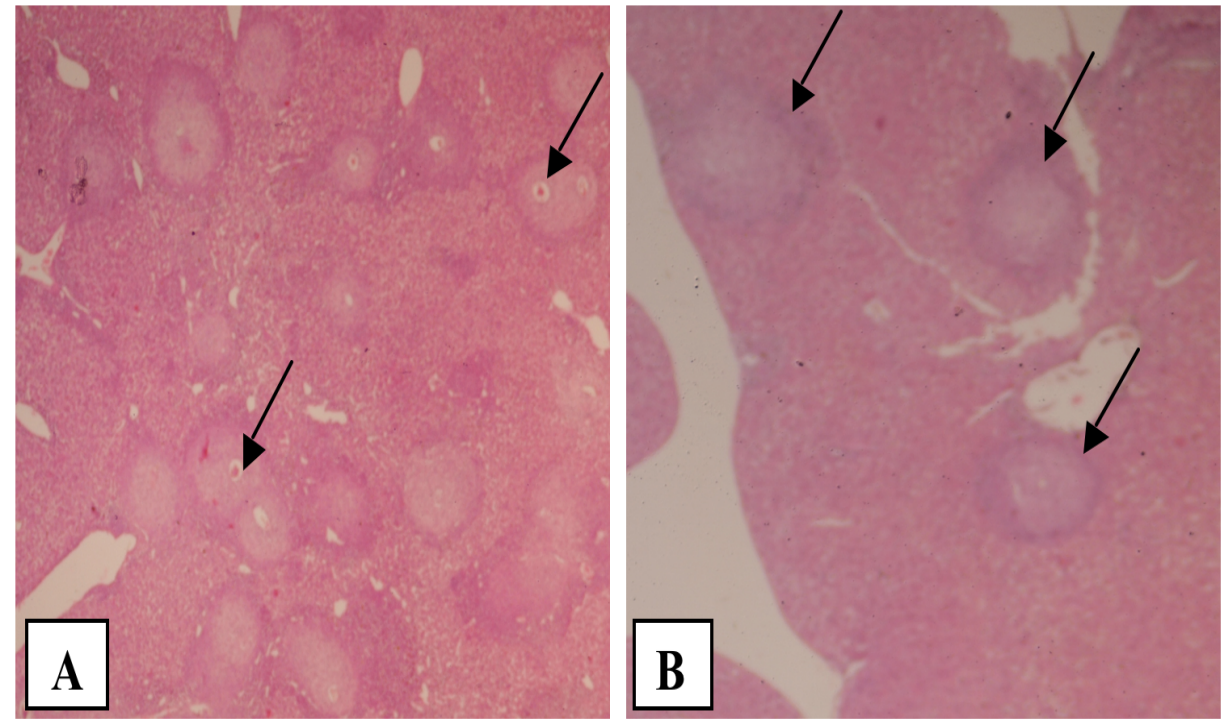

Figure (1): Histopathological study of liver sections of Schistosoma mansoni-infected mice euthanized 10 weeks post infection (H\&E*40). (A) Section from infected non-treated mice group showing large number of granuloma with irregular outline. Arrows point to eggs in granuloma. (B) Section from mice treated with PZQ (500 mg/kg/day 6 WPI for 2 successive days) showing small number of large sized granuloma with no eggs in the center. Arrows point to granuloma.

Vol. 43, No. 1 \& 2 Jan. \& April, 2014 

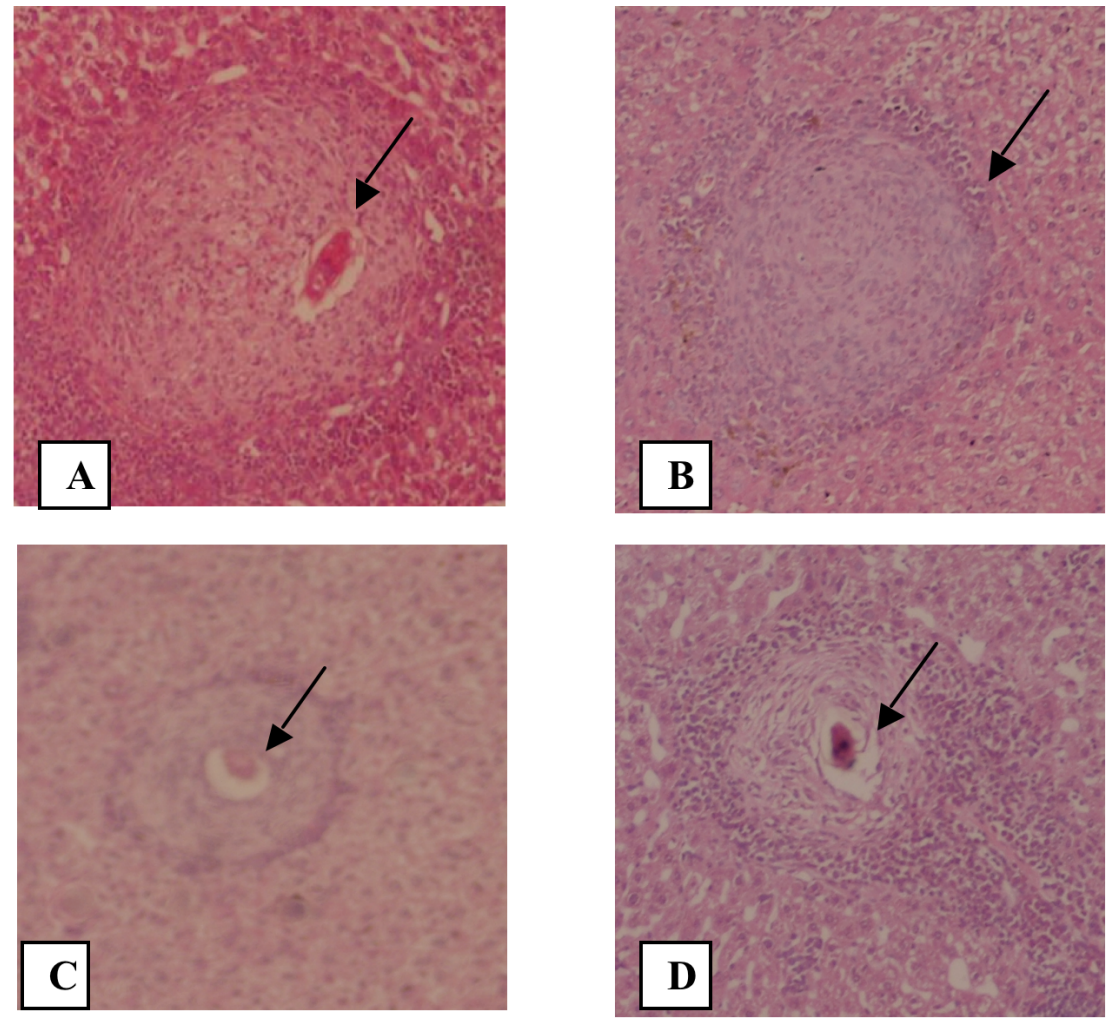

Figure (2): Histopathological study of liver sections of Schistosoma mansoni-infected mice euthanized 10 weeks post infection (H\&E*100). (A) Section from infected non-treated mice group showing large sized granuloma with irregular outline. Arrow points to egg in granuloma. (B) Section from mice treated with PZQ (500 mg/kg/day 6 WPI for 2 successive days) showing large sized granuloma with irregular outline. Arrow points to granuloma. (C) Section from mice treated with IS-5-MN showing small sized concised granuloma and reduced inflammatory cell infiltrate. Arrow points to egg in granuloma. (D) Section from mice treated with IS-5-MN and PZQ showing small sized concised granuloma. Arrow points to egg in granuloma. 


\section{DISCUSSION}

Schistosomiasis affects about 240 million people worldwide and is considered the most frequent cause of liver fibrosis [2]. In schistosomiasis, liver damage takes place $5 \mathrm{WPI}$, coincident with the onset of oviposition. Eggs that are trapped within the liver provoke a chronic granulomatous inflammatory response [22]. Inflammation and fibrosis accompanied with vascular changes underlie liver pathology in schistosomiasis from the very early scattered periovular granulomas to the advanced periportal fibrosis with its sequelae [23]. It is worth noting that antischistosomal drugs successfully eradicate adult parasites with minimal improvement in liver pathology that is related to parasitological cure [24]. So, other medications that can target the scarring process are urgently needed to prevent progression to irreversible cirrhosis [25].

Progressive liver fibrosis is principally maintained by chronic activation of the wound healing response and oxidative stress [26]. Among the most commonly used NO donors, organic nitrates as IS-5-MN is widely used as long acting anti-ischaemic vasodilator drug. Vasodilator proper- ties of IS-5-MN are mediated through NO release [27]. In turn, NO is involved in each stage of wound healing process through modulating inflammation, angiogenesis, cell proliferation, matrix deposition, and remodeling [28]. In addition to the documented anti-microbial properties of NO [29], the drug can be tested in liver fibrosis model of schistosomiasis both as anti-fibrotic and as antischistosomal drug.

To our knowledge, this is the first study evaluating the effects of the NO donor IS-5-MN on an experimental model of $\mathrm{S}$. mansoni.

In the current study, IS-5-MN administered alone did not cause significant alterations in the oogram pattern, indicating that the drug does not have anti-schistosomal activity; (Table 1), since alteration in the oogram pattern is one of the most important parameters expressing the activity of anti-schistosomal drugs [18].

Nitric oxide can have a cytoprotective or cytotoxic effect. This depends on the initial injury, the source, rate of production, the balance between NO and other inflam- 
matory cytokines and mediators e.g. in previous studies e.g. El-Lakkany TNF- $\alpha$, IL- $1 \beta$, IFN- $\gamma$ and reactive oxygen species (ROS), and concentration in the tissues [30]. NO exerts a protective role under oxidative stress resulting from ROS. It was documented that only microM levels of $\mathrm{NO}$ are required to protect against these ROS [31].

Administration of IS-5-MN alone did not increase NO level because the drug did not possess antischistosomal activity, resulting in persistent state of oxidative stress. On the other hand, PZQ exerted anti-schistosomal effect but did not significantly alter inflammation and necrosis. Combined administration of IS-5-MN and PZQ induced a synergistic effect and significantly increased NO level, in comparison with infected non-treated group, because of the combination of antischistosomal activity of $P Z Q$ and the hepatoprotective effect of NO donation caused by IS-5-MN (Table 2).

Significant amelioration of the parenchymatous changes in IS-5-MN administered group could be visualized in the context of antiinflammatory properties of NO. Other anti-inflammatory drugs were tested et al. [32] who reported the effect of silymarin as an anti-inflammatory and anti-fibrotic agent alone and in combination with PZQ on schistosomiasis mansoni-infected mice.

Co-administration of PZQ and IS5-MN diminished granuloma number and size, when compared to infected non-treated mice. Our results run in parallel with those recorded by Abdel-Hafeez et al. [33], who documented reduced granuloma number, in response to PZQ only, and diminished size and number following combined alpha lipoic acid and PZQ therapy. Also, similar findings were published by Wang et al. [34], who investigated the effect of vitamin $E$ administration in $S$. japonicum-infected mice, and documented improvement of liver pathology following vitamin E supply, and reduced granuloma count and size.

Our results are in line with previous studies using another NO donor drug S-Nitroso-N-acetylcysteine (SNAC) as an effective anti-fibrotic agent in Sprague-Dawley rats [35]. Also, in another study, sodium nitroprusside; one of NO donors in combination with mesenchymal stem cell

MANSOURA MEDICAL JOURNAL 
(MSC) transplantation increased MSC ability to repair fibrotic liver as a consequence of NO induced HSC apoptosis [36]. Results of the present study reinforce results of a previous study from Egypt showing marked reduction of $\mathrm{CCl} 4$ induced liver fibrosis after treatment with IS-5-MN alone or in combination with the anti-oxidant silymarin [13].

\section{Conclusion}

In conclusion, combined IS-5-MN and PZQ therapy attenuated $S$. mansoni-inuced liver pathology in a mouse model by increasing NO generation, and decreasing granuloma size and number. Further studies are recommended to determine the actual pathways responsible for all different activities of IS5-MN. Moreover, clinical studies should be carried out to reveal the real efficacy of this adjuvant therapy.

\section{Acknowledgment}

Our utmost gratitude to Dr. Mohamed A. Sobh, Director of the Medical Experimental Research Center (MERC), Faculty of Medicine, Mansoura University, Egypt, for pro- viding all facilities required during the study. We acknowledge the assistance of all staff at MERC, peculiarly the generous help of Dr. Basma $\mathbf{H}$. Othman with animal experimentation.

\section{REFERENCES}

1. Gryseels $B$, Polman $K$, Clerinx J, Kestens L (2006) : Human schistosomiasis. Lancet, 368 (9541) : 11061118.

2. Inobaya MT, Olveda RM, Chau TNP, Olveda DU, Ross AGP (2014): Prevention and control of schistosomiasis: a current perspective. Res Rep Trop Med, 2014 (5): 65-75.

3. Cheever AW, Hoffmann KF, Wynn TA (2000) : Immunopathology of schistosomiasis mansoni in mice and men. Immunol Today, 21 (9): 465-466.

4. Cheever AW (1968) : A quantitative post-mortem study of 
schistosomiasis mansoni in man. Am J Trop Med Hyg, 17 (1): 38-64.

5. Tache DE, Stanciulescu CE, Banita IM, Purcaru SO, Andrei AM, Comanescu V, Pisoschi CG (2014) : Inducible nitric oxide synthase expression (iNOS) in chronic viral hepatitis and its correlation with liver fibrosis. Rom J Morphol Embryol, 55(2 Suppl): 539543.

\section{Gutiérrez-Ruiz M C, Gómez-} Quiroz LE (2007) : Liver fibrosis: Searching for cell model answers. Liver Int, 27 (4): 434-439.

7. Xu J, Liu X, Koyama Y, Wang P, Lan T, Kim IG, Kim IH, Ma HY, Kisseleva T (2014) : The types of hepatic myofibroblasts contributing to liver fibrosis of different etiologies. Front Pharmacol, 5: 167.

8. Aram G, Potter JJ, Liu X, Torbenson MS, Mezey $E$ (2008) : Lack of inducible nitric oxide synthase leads to increased hepatic apoptosis and decreased fibrosis in mice after chronic carbon tetrachloride administration. Hepatology, 47 (6): 2051-2058.

9. Failli P, DeFRANCO RM, Caligiuri A, Gentilini A, Romanelli RG, Marra F, Batignani $G$, Guerra $C T$, Laffi G, Gentilini P, Pinzani M (2000) : Nitrovasodilators inhibit platelet-derived growth factor-induced proliferation and migration of activated human hepatic stellate cells. Gastroenterology, 119 (2): 479-492.

10. Pastor CM, Losser MR, Payen D (1995) : Nitric oxide donor prevents hepatic and systemic perfusion decrease induced by endotoxin in anesthetized rabbits. Hepatology, 22 (5): 15471553.

11. Loureiro-Silva MR, Cadelina GW, Iwakiri Y, Groszmann RJ (2003) : A liverspecific nitric oxide donor improves the intra-hepatic vascular response to both MANSOURA MEDICAL JOURNAL 
portal blood flow increase and methoxamine in cirrhotic rats. J Hepatol, 39 (6): $940-946$.

12. Fiorucci S, Antonelli E, Distrutti E, Mencarelli A, Farneti S, Del Soldato $\mathbf{P}$, Morelli A (2004) : Liver delivery of NO by NCX1000 protects against acute liver failure and mitochondrial dysfunction induced by APAP in mice. $\mathrm{Br} J$ Pharmacol, 143 (1): 33-42.

13. Abdel Salam OM, Sleem AA, Shafee $N$ (2010) : Hepatoprotective effects of the nitric oxide donor isosorbide-5-mononitrate alone and in combination with the natural hepatoprotectant, silymarin, on carbon tetrachloride-induced hepatic injury in rats. Inflammopharmacology, 18 (2): 87-94.

14. Rassaf, T, Kelm M (2013): Isosorbide-5-mononitrate and endothelial function: a wolf in sheep's clothing. Eur Heart J, 34 (41): 31733174.

Vol. 43, No. 1 \& 2 Jan. \& April, 2014
15. Smithers SR, Terry RJ (1965) : The infection of laboratory hosts with cercariae of Schistosoma mansoni and the recovery of the adult worms. Parasitology, 55 (4): 695-700.

16. Paget GE, Barnes JM (1964) : In: Evaluation of Drug Activities Pharmacometics, DR Laurence, AL Bacharach (Eds.), (pp. 1-135). Academic Press: London \& NewYork.

17. Gönnert R, Andrews P (1977) : Praziquantel, a new broad-spectrum antischistosomal agent. Z Parasitenkund, 52, 129-150.

18. Pellegrino J, Oliveira CA, Faria J, Cunha AS (1962) : New approach to the screening of drugs in experimental schistosomiasis mansoni in mice. Am J Trop Med Hyg, 11: 201215.

19. Tandra S, Yeh MM, Brunt EM, Vuppalanchi R, Cum- 
mings $\mathbf{O} \mathbf{W}$, Unalp-Arida

A, Wilson LA, Chalasani N (2011) : Presence and significance of microvesicular steatosis in nonalcoholic fatty liver disease. J Hepatol, 55 (3): 654-659.

\section{Suzuki S, Toledo-Pereyra LH}

(1993) : Monoclonal antibody to intercellular adhesion molecule 1 as an effective protection for liver ischemia and reperfusion injury. Transplant Proc, 25 (6): 3325-3327.

21. Poo JL, Hernández-Pando R, Diliz H, Morales L, Marin E, Panduro A, Kershenobich D, Uribe M (1992) : Semiquantitative histologic evaluation of the liver in patients after liver transplantation. Transplant Proc, 24 (5): 1973-1975.

22. Andrade ZA (2004) : Schistosomal hepatopathy. Mem Inst Oswaldo Cruz, 99 (5 Suppl 1): 51-57.

23. Andrade ZA (2009) : Schistosomiasis and liver fibrosis.
Parasite Immunol, 31 (11): 656-663.

24. Berhe N, Myrvang B, Gundersen SG (2008) : Reversibility of schistosomal periportal thickening/fibrosis after praziquantel therapy: a twenty-six month followup study in Ethiopia. Am J Trop Med Hyg, 78 (2): 228234.

25. Albanis E, Safadi R, Friedman SL (2003) : Treatment of hepatic fibrosis: almost there. Curr Gastroenterol Rep, 5 (1): 48-56.

26. Parola M, Marra F, Pinzani M (2008) : Myofibroblast-like cells in liver fibrogenesis: Emerging concepts in a rapidly moving scenario. Mol Aspects Med, 29 (1-2): 58-66.

27. Johal T, Lees CC, Everett RT, Wilkinson BI (2014) : The nitric oxide pathway and possible therapeutic options in pre-eclampsia. $\mathrm{Br} J$ Clin Pharmacol, 78 (2): 244-257.

MANSOURA MEDICAL JOURNAL 
28. Rizk M, Witte MB, Barbul A (2004) : Nitric oxide and wound healing. World $\mathrm{J}$ Surg, 28 (3): 301-306.

29. Carpenter AW, Schoenfisch MH (2012) : Nitric oxide release: part II. Therapeutic applications. Chem Soc Rev, 41 (10): 3742-3752.

30. Brunet LR, Beall M, Dunne DW, Pearce EJ (1999) : Nitric oxide and the Th2 response combine to prevent severe hepatic damage during Schistosoma mansoni infection. J Immunol, 163 (9): 4976-4984.

31. Wink DA, Cook JA, Pacelli R, Liebmann J, Krishna MC, Mitchell JB (1995) : Nitric oxide (NO) protects against cellular damage by reactive oxygen species. Toxicol Lett, 82-83: 221-226.

32. El-Lakkany NM, Hammam OA, El-Maadawy WH, Badawy AA, Ain-Shoka AA, Ebeid FA (2012) : Antiinflammatory/anti-fibrotic effects of the hepatoprotective silymarin and the schistosomicide praziquantel against Schistosoma mansoni-induced liver fibrosis. Parasit Vectors, 5: 9.

33. Abdel-Hafeez EH, Ahmad AK, Abdulla AM, AabdelWahab S, Mosalem FA (2012) : Therapeutic effect of alpha lipoic acid combined with praziquantel on liver fibrosis induced by Schistosoma mansoni challenged mice. Parasitol Res, 111 (2): 577-586.

34. Wang $X$, Zhang $\mathrm{R}$, Du J, Hu Y, Xu L, Lu J, Ye S (2011) : Vitamin $\mathrm{E}$ reduces hepatic fibrosis in mice with Schistosoma japonicum infection. Mol Med Rep, 5 (2): 465-468.

35. Mazo DF, de Oliveira MG, Pereira IV, Cogliati B, Stefano JT, de Souza GF, Rabelo F, Lima FR, Ferreira Alves VA, Carrilho FJ, de Oliveira CP (2013) : S-nitroso-N-acetylcysteine attenuates liver fibrosis in experimental non- 
Samar M. Alhusseiny et al...

alcoholic steatohepatitis.

Drug Des Devel Ther, 7:

553-563.

36. Ali G, Mohsin S, Khan M, Nasir GA, Shams S, Khan
SN, Riazuddin S (2012) : Nitric oxide augments mesenchymal stem cell ability to repair liver fibrosis. J Transl Med, 10: 75. 


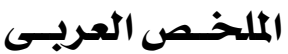

\author{
التأثير الواقي لأكسيد النيتريك للكبد في البلهاربييا \\ المعوية التجريبية في الفئران \\ م.م. سمر الحسيني** ، أ.د / سمر البشبيشيث \\ أ.د / مها أبو هاشم *** ، أ.د / حسام الدين النهرر* \\ د / عبير الحناوى * أ.د / آية حندوسـة*
}

من قسهى الطفيليات الطبية والبـاثولوجى** ـ كلية الطب - جامعة المنصورة.

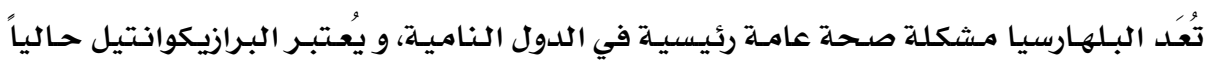

الاختيار الأمثل لعلاج البلهارسيا في الإنسان، و يُعَد الأيزوسوريـيــ-هـ أحسادي النترات من المركبات

التي تحتوي على النـيتـروجين و الأكســين و يتتم تأيـيضه عن طريق الانزيهات لتحـريـر أكسيد

النيتريك ليقوم بتأثيراته الدوائية.

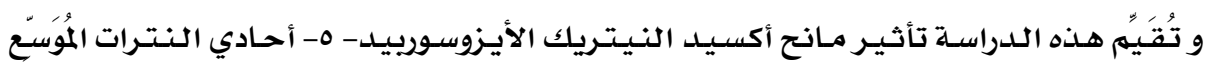

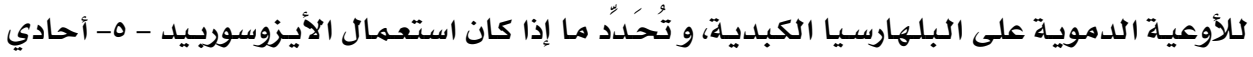

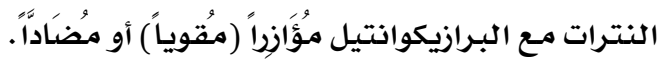

و قد تم تقسيه إناث الفئران البيضاء إلى خمس مجمموعات:

- مجموعة ا : فئران غير مصابة (مجموعة ضابطة).

- مجمموعة ץ: فئران مصابة بالبلهارسيا المعوية (مصابة، غير معالجـة).

- مـجموعة ب: فئران مصابة و تمت معالجتها بالبرازيكوانتيل بعد 7 أسابيع من العدوى.

- مجـموعة ؛: فئران مصابة و تـمت معـالجتها بالأيزوسوريـيد-ه- أحادي النتـرات من الأسبوع

الرابع حتى الأسبوع العاشر من العدوي (لمدة V أسابيع) .

Vol. 43, No. 1 \& 2 Jan. \& April, 2014 


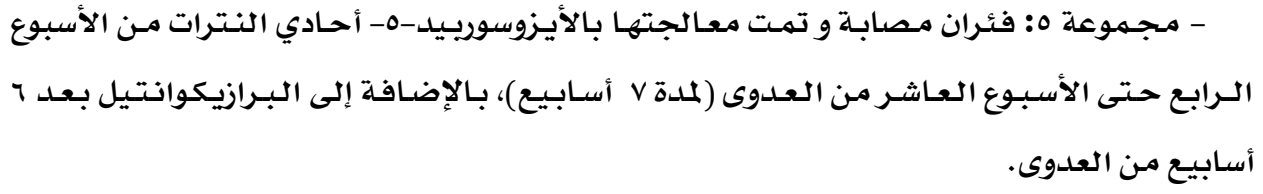

MANSOURA MEDICAL JOURNAL 